\title{
Efeitos genéticos aditivos diretos e maternos e heterozigóticos sobre os desempenhos pré e pós-desmama em uma população multirracial Aberdeen Angus × Nelore
}

\section{Carlos Júnior Kippert ${ }^{1}$, Paulo Roberto Nogara Rorato ${ }^{2}$, Jader Silva Lopes ${ }^{3}$, Tomás Weber ${ }^{4}$, Arione Augusti Boligon 5}

\author{
${ }^{1}$ Curso de Pós-Graduação em Zootecnia da UFSM. \\ 2 Departamento de Zootecnia da UFSM. \\ ${ }^{3}$ Curso de Graduação em Zootecnia da UFSM. Bolsista PIBIC-CNPq. \\ 4 Curso de Pós-Graduação em Zootecnia da UFSM. Bolsista CAPES. \\ ${ }^{5}$ Curso de Pós-Graduação em Genética e Melhoramento Animal da FCAV/UNESP - Jaboticabal.
}

RESUMO - Objetivou-se avaliar os efeitos aditivos direto e materno e os efeitos não-aditivos e heterozigóticos sobre os desempenhos pré e pós-desmama e desenvolver equações para predizer o desempenho de genótipos de uma população multirracial Aberdeen Angus (Angus) $\times$ Nelore. Nas análises, foram utilizados dois modelos. O modelo 1 foi adotado para as características pré-desmama peso à desmama ajustado para 205 dias (P205) e ganho de peso médio diário do nascimento à desmama (GMDND), considerando fixos os efeitos de grupo de contemporâneos (GC) e de grupo genético (GG), além das co-variáveis idade do bezerro à desmama (IBD) e idade da vaca ao parto (IVP). Para as características pós-desmama peso ao sobreano ajustado para 550 dias de idade (P550) e ganho médio de peso da desmama ao sobreano (GMDDS), utilizou-seo mesmo modelo, apenas substituindo a co-variável IBD pela idade do bezerro ao sobreano (IBS). O modelo 2 (M2), de regressão múltipla, foi utilizado depois que os dados foram ajustados para GC, IVP e IBD (P205) ou IBS (P550) e contemplou os efeitos genéticos aditivos diretos e maternos de raça e os efeitos de heterozigoses direta e materna. Os resultados das análises comprovaram diferenças entre os cruzamentos, uma vez que os animais com elevada heterozigose materna apresentaram melhor desempenho para P205 e GMDND, tendência semelhante à observada para a heterozigose direta. A influência do efeito direto sobre as características P550 e GMDDS foi maior que a do efeito materno. Os efeitos aditivos diretos da raça Angus determinaram maior desempenho. Não houve diferença significativa entre os valores estimados pelo modelo 1 e os preditos pelo modelo 2 para P205, P550 e GMDDS.

Palavras-chave: estimativa e predição de desempenhos, heterose, multicolinearidade, regressão múltipla

\section{Direct, maternal additive genetic and heterozygotic effects for pre- and post-weaning traits in a multi-breed Aberdeen Angus-Nelore population}

\footnotetext{
ABSTRACT - The objective of this study was to estimate direct and maternal additive genetic, non-additive and heterozygotic effects for pre and post-weaning traits and to develop equations to predict growth performance in a multi-breed Aberdeen Angus (Angus)-Nellore herd. The analyses were performed by SAS ${ }^{\circledR}$ using two different models. The model 1 (M1) was used for the pre-weaning traits, weaning weight adjusted to 205 days of age (P205) and average daily gain from birth to weaning (GMDND), and included the fixed effects of contemporary groups (GC), genetic groups (GG) and the covariates age of calf at weaning (IBD) and age of cow at calving (IVP). The same model except for replacing the covariate IBD by age of calf at yearling (IBS) was used for the post-weaning traits - yearling weight adjusted to 550 days of age (P550) and average daily gain from weaning to yearling (GMDDS). A multiple regression model(M2) was used after adjusting the data for GC, IVP and IBD (P205) and IBS (P550) effects and included the breed direct and maternal additive and the direct and maternal heterozygotic effects. Animals with higher maternal heterozygosis performed better for P205 and GMDND. A similar trend was observed for the direct heterozygosis. The direct genetic effect was larger than the maternal genetic effect for P550 and GMDDS. The additive direct effect determined better performances in the Angus breed. Differences between the estimated (M1) and predicted (M2) averages for P205, P550 and GMDDS were not significant.
}

Key Words: heterosis, multicolinearity, multiple regression, performance estimation and prediction

Este artigo foi recebido em 11/9/2006 e aprovado em 4/3/2008.

Correspondências devem ser enviadas para rorato@smail.ufsm.br. 


\section{Introdução}

O Brasil é um país de proporções continentais e, por isso, apresenta grande diversidade de solo, clima e cultura, entre outras. As diversas combinações entre estes fatores possibilitam um grande número de possibilidades de sistemas de produção pecuária. Além disso, as raças bovinas existentes representam múltiplos biótipos, o que permite a adequação dos animais aos ambientes em que serão criados, principalmente em casos de cruzamentos entre raças. Segundo Alencar et al. (1995), é necessário identificar os cruzamentos com maior heterose e que combinam características econômicas desejáveis para determinados tipos de manejo e regiões do País.

A incorporação de genes de diferentes raças em um mesmo indivíduo promove ganhos por dominância, mas provoca perdas por recombinação gênica. No animal cruzado, portanto, manifestam-se todas as formas de ação gênica e o balanço líquido entre efeitos de dominância e as perdas por recombinação é normalmente estimado e interpretado como heterose (Fries et al., 2000).

Barbosa \& Alencar (1995), sintetizando resultados de estudos de cruzamentos conduzidos no Brasil no período de 1934 a 1994, observaram melhor desempenho dos animais mestiços obtidos do cruzamento entre raças européias e zebuínas em comparação aos zebuínos puros. Comparando cruzamentos entre as raças Charolês e Nelore, Alencar et al. (1998) observaram maiores pesos ao nascimento e à desmama nos produtos do cruzamento em comparação à raçaNelore. Verificaram ainda que as diferenças entre os produtos dos cruzamentos e os de raça definida e dos grupos de composições genéticas diferentes dependiam das porcentagens de genes da raça Charolês e de heterozigose materna e individual na constituição dos animais. Roso \& Fries (2000) afirmaram que a superioridade dos produtos de cruzamentos em relação à média da contribuição paternal das raças puras é resultado da heterose e da complementari-dade entre as raças.

A produção de leite das vacas é importante na pecuária de corte, uma vez que grande parte dos nutrientes ingeridos pelos bezerros nos primeiros meses de vida é proveniente do leite materno, responsável por uma porção significativa da variação no peso à desmama e no ganho de peso do nascimento à desmama (Alencar, 1989; Albuquerque et al., 1993). Meyer et al. (1994) afirmaram que a produção de leite é o efeito materno que mais afeta o bezerro até a idade da desmama e que as diferenças raciais estão intimamente relacionadas à produção leiteira. Vacas resultantes de cruzamentos tendem a apresentar maior produção de leite e, portanto, seus bezerros podem expressar melhor seu potencial de crescimento (Skrypzeck, 2000).

Comparando o desempenho à desmama do primeiro produto de novilhas resultantes do cruzamento entre a raça Hereford e quatro raças zebuínas no Rio Grande do Sul, Leal (2000) relatou que as novilhas Holandês $\times$ Nelore produziram bezerros mais pesados. Quando considerou a relação de peso mãe $\times$ filho, observou melhor desempenho para o genótipo Holandês $\times$ Gir.

Existem poucos trabalhos para avaliação, ao sobreano, de animais cruzados (Muniz \& Queiroz, 1999), provavelmente porque grande parte desses animais não pertence mais ao rebanho de origem, ou não possui as informações necessárias para o melhoramento genético do plantel nesta fase.

Este estudo foi realizado com os objetivos de estudar os efeitos de grupo genético sobre o peso ajustado para 205 e para 550 dias de idade e sobre o ganho médio diário do nascimento à desmama e da desmama ao sobreano e desenvolver equações para predizer o desempenho de genótipos de uma população Aberdeen Angus (Angus) $\times$ Nelore participante de um programa de melhoramento genético.

\section{Material e Métodos}

O estudo foi realizado com um banco de dados fornecido por Gensys Consultores Associados S/C e Natura Genética Sul Americana. O arquivo original continha informações sobre o desempenho de 121.241 bezerros filhos de 1.359 touros e 84.465 vacas das raças Aberdeen Angus (Angus) e Nelore e de diversos grupos genéticos possíveis por meio do cruzamento entre elas. Os dados foram coletados em 75 fazendas dos estados de Goiás, Minas Gerais, Mato Grosso do Sul, Paraná, Rio Grande do Sul, São Paulo e Tocantins nos anos de 1986 a 2002.

$\mathrm{Na}$ editoração dos dados, foram criadas as variáveis: peso ajustado para 205 (P205) e para 550 (P550) dias de idade; ganho médio diário de peso do nascimento à desmama (GMDND) e da desmama ao sobreano (GMDDS); grupos de contemporâneos (GC) - agrupamento dos animais nascidos em mesma fazenda (1 a 75), ano (1986 a 2002) e estação de nascimento ( 1 a 4 = primavera, verão, outono e inverno para P205; e 1 a 2 = primavera-verão e outono-inverno - para P550), sexo (F e M) e grupo de manejo até a desmama (1 a 388) e da desmama ao sobreano (1 a 129); grupos genéticos (GG) - proporção dos genes contribuintes da raça Nelore para o bezerro, o touro (pai) e a vaca (mãe), obtidos pela concatenação das proporções genéticas dos três e, desta forma, tornando possível diferenciar bezerros com mesmo 
efeito aditivo da raça, mas provenientes de diferentes cruzamentos. Estabeleceu-se que cada grupo de contemporâneos fosse constituído de pelo menos duas classes de grupos genéticos e que cada grupo genético contivesse pelo menos dois grupos de contemporâneos no intuito de evitar o confundimento dos dois efeitos. Foram então formados 650 grupos de contemporâneos e 33 grupos genéticos. Excluíram-se os dados de grupos de contemporâneos com menos de cinco animais, de touros com menos de dez filhos, de vacas que pariram com menos de três ou com mais de 20 anos de idade e de animais com paternidade desconhecida.

Os arquivos analisados foram constituídos dos pesos de 96.502 animais, filhos de 962 touros e de 67.231 vacas, para P205 e GMDND, distribuídos em 2.542 grupos de contemporâneos e 45 grupos genéticos e de 40.310 animais filhos de 720 touros e 31.136 vacas para P550 e GMDDS, distribuídos em 650 grupos de contemporâneos e 33 grupos genéticos.

Os dados foram analisados utilizando-se dois modelos estatísticos. O primeiro foi:

$$
\begin{gathered}
Y_{\mathrm{ijklm}}=\mu+\mathrm{GC}_{\mathrm{i}}+\mathrm{GG}_{\mathrm{j}}+\beta_{1} \mathrm{ID}+\beta_{2} \mathrm{ID}^{2}+\beta_{3} \mathrm{IV}+\beta_{4} \mathrm{IV}^{2}+ \\
\varepsilon_{\mathrm{ijklm}},(\mathrm{M} 1)
\end{gathered}
$$

em que: $Y_{i j k l m}=$ observação do peso ajustado para as idades de 205 (P205) ou 550 (P550) dias e do ganho médio diário de peso do nascimento à desmama (GMDND) ou da desmama ao sobreano (GMDDS) do m-ésimo animal; $\mu=$ média geral da característica; $\mathrm{GC}_{\mathrm{i}}=$ efeito do i-ésimo grupo de contemporâneos; $\mathrm{GG}_{\mathrm{j}}=$ efeito do j-ésimo grupo genético, $\beta_{1}$ e $\beta_{2}=$ coeficientes de regressão linear $(L)$ e quadrático $(\mathrm{Q})$, respectivamente, para idade do bezerro à desmama (IBD); $\beta_{3}$ e $\beta_{4}=$ coeficientes de regressão L e $Q$, respectivamente, para idade da mãe ao parto (IMP); e $\varepsilon_{\mathrm{ijklm}}=$ erro aleatório associado a cada observação (NID, $\left.0, \delta^{2}\right)$. Para análise dos dados, utilizou-se o procedimento PROC GLM (SAS, 2001). Para P550 e GMDDS, a idade do bezerro à desmama (IBD foi substituída no modelo 1 pela idade do bezerro ao sobreano (IBS), efeito L, uma vez que o Q não foi significativo.

Depois que os dados foram ajustados para os efeitos de grupo de contemporâneo, idade do bezerro à desmama (P205) ou idade do bezerro ao sobreano (P550) e IVP, realizou-se uma análise de regressão múltipla pelo procedimento PROC REG (SAS, 2001), utilizando-se o modelo:

$$
\begin{gathered}
\mathrm{Y}_{\mathrm{ijklm}}=\beta_{0}+\beta_{1} \mathrm{EDR}+\beta_{2} \mathrm{EMR}+\beta_{3} \mathrm{HD}+\beta_{4} \mathrm{HM}+ \\
\varepsilon_{\mathrm{ijklm}}(\mathrm{M} 2)
\end{gathered}
$$

em que: $\beta_{0}=$ constante (intercepto); $\beta_{1}=$ coeficiente de regressão L para efeito aditivo direto de raça (EDR), $\beta_{2}=$ coeficiente de regressão L para efeito aditivo materno de raça $(E M R) ; \beta_{3}=$ coeficiente de regressão $L$ para heterozigose direta (HD); $\beta_{4}=$ coeficiente de regressão L para heterozigose materna $(\mathrm{HM}) ; \varepsilon_{\mathrm{ijklm}}=$ erro associado a cada observação.

$\mathrm{O}$ efeito aditivo de raça correspondeu ao percentual de genes da raça Nelore presente no animal, que variou de 0 $(0 \%)$ a $1(100 \%)$.

O erro-padrão da regressão múltipla foi calculado de acordo com a equação:

$$
\text { SEpred }=\hat{\sigma}\left(1+\frac{1}{n}+\frac{(\hat{x}-\bar{x})^{2}}{S x x}\right)
$$

em que: SEpred = erro-padrão do valor predito; $\hat{\sigma}=$ raiz quadrada da variância do erro; $n=$ número de observações; $\hat{x}=$ valor predito; $\bar{x}=$ médias dos valores preditos; e $S x x=$ soma de quadrados dos valores preditos corrigida para a média.

Os efeitos de heterozigose direta (HD) foram obtidos utilizando-se a equação proposta por Wolf et al. (1995):

$$
\mathrm{HD}=\mathrm{a}_{i}^{t} \mathrm{a}_{j}^{v}+\mathrm{a}_{j}^{t} \mathrm{a}_{i}^{v}
$$

em que $\alpha_{i}^{t}$ e $\alpha_{i}^{v}$ denotam a proporção de genes da raça ' $\mathrm{i}$ ' no pai e na mãe do bezerro, respectivamente. Entretanto, para a definição de heterozigose materna, foram admitidos valores teóricos, uma vez que, neste caso, não era conhecido o grupo genético (avôs e avós) que deu origem às mães.

Para o cálculo da heterozigose, é necessária a utilização dos efeitos aditivos de raça, que podem apresentar correlação linear (multicolineariedade), que promove inflação na variância de $\alpha$. De acordo com Roso et al. (2005), uma forte correlação entre as variáveis faz com que os coeficientes de regressão obtidos pelo método dos quadrados mínimos apresentem elevados erros-padrão, sinais opostos ao esperado, e sejam muito sensíveis às mudanças na população analisada ou às alterações das variáveis incluídas no modelo. Segundo Dias et al. (2003), a ocorrência de multicolinearidade deve ser testada, uma vez que, em caso positivo, os testes estatísticos podem falhar em detectar diferenças significativas entre os fatores. A ocorrência de multicolinearidade foi avaliada pelo cálculo do fator de inflação da variância (FIV), segundo equação [1/(1-R $\left.\left.{ }^{2}\right)\right]$ descrita por Freund \& Wilson (1998), em que $\mathrm{R}^{2}$ é o coeficiente de determinação. Segundo esses autores, FIV maior que 10 indica a ocorrência de multicolineariedade.

Como os avós maternos não eram conhecidos, a heterozigose materna foi calculada considerando que as mães do grupo genético $1 / 2$ Nelore-Angus apresentavam $100 \%$ de heterozigose e que esse percentual é variável de acordo com a proporção de cada uma das duas raças envolvidas na formação do grupo genético. 
A significância estatística da diferença entre as médias estimadas pelo modelo 1 e as preditas pelo modelo 2 foi testada pelo teste t de Student (SAS, 2001).

\section{Resultados e Discussão}

Todas as fontes de variação tiveram efeito significativo $(\mathrm{P}<0,05)$ sobre as características P205, P550, GMDND e GMDDS estimadas pelo modelo 1. Os resultados obtidos neste estudo para P205 e GMDND foram similares aos relatados por Perotto et al. (2000) para as raças Angus e seus cruzamentos recíprocos. Esses autores verificaram efeito significativo de IVP (Le Q) sobre P210 e GMDND. Do mesmo modo, Muniz \& Queiroz (1998) relataram efeito significativo de IVP (L e Q) sobre o desempenho até a desmama em animais resultantes de cruzamentos. Os resultados obtidos para P550 e GMDDS confirmam parcialmente os descritos por Campos \& Fries (1989), que relataram efeitos significativos da IVP (L e Q) sobre P550 para a raça Hereford e os encontrados por Muniz \& Queiroz (1999), que verificaram efeito significativo da IVP sobre o ganho médio diário até 550 dias de idade.

As médias ajustadas (M1) variaram de $162 \mathrm{~kg}$ (Nelore) a $183 \mathrm{~kg}$ (5/8 Nelore, filhos de vacas $1 / 2$ Nelore) para P205 e de $645 \mathrm{~g} /$ dia (3/16 Nelore, filhos de vacas Angus) a $753 \mathrm{~g} / \mathrm{dia}$ (5/8 Nelore, filhos de vacas $1 / 2$ Nelore) para GMDND (Tabela 2). As maiores médias para P205 (183 kg) e GMDND (753 g/dia) foram observadas nos animais $5 / 8$ Nelore filhos de vacas $1 / 2$ Nelore, o que evidencia a superioridade desses animais relacionada à influência da heterozigose materna, que, neste caso, é máxima, sobre o desempenho da progênie. Resultados similares foram relatados por Perotto et al. (2000) para o cruzamento entre as raças Canchim e Angus no estado do Paraná. Esses autores concluíram que os animais 11/16
Canchim apresentaram maiores pesos ao nascer, porém, o maior peso à desmama foi verificado em animais $1 / 2$ Canchim, neste caso com a heterose materna nula.

As médias ajustadas (M1) variaram de $259 \mathrm{~kg}$ ( $1 / 2$ Nelore, filhos de vacas $3 / 8$ Nelore) a $334 \mathrm{~kg}(1 / 2$ Nelore, filhos de vacas Nelore) para P550 e de $271 \mathrm{~g} / \mathrm{dia}$ ( $1 / 2$ Nelore, filhos de vacas $3 / 8$ Nelore) a $440 \mathrm{~g} /$ dia ( $1 / 2$ Nelore, filhos de vacas Nelore) para GMDDS (Tabela 2).

As maiores médias para P550 e GMDDS foram observadas nos animais $1 / 2$ Nelore (filhos de vacas Nelore) e foram 29 e $62 \%$ superiores, respectivamente, aos menores valores observados nos animais $1 / 2$ Nelore (filhos de vacas $3 / 8$ Nelore). Os valores extremos ocorreram no mesmo grupo genético, evidenciando a importância e a necessidade da utilização dos efeitos genéticos aditivos de raça e de heterozigose, tanto direta quanto materna, na predição do desempenho de cruzamentos, uma vez que, teoricamente, esses animais possuem o mesmo efeito aditivo de raça, mas apresentam desempenhos diferentes. Avaliando o desempenho em pastagem cultivada no período pósdesmama de animais produtos do cruzamento entre vacas da raça Hereford e touros das raças Nelore e Angus, entre outros, Paschal et al. (1994) relataram que os maiores pesos foram obtidos em bezerros resultantes de cruzamentos entre raças zebuínas e taurinas. As diferenças foram ainda maiores com baixa disponibilidade e qualidade da forragem, comprovando maior adaptação dos animais originados deste cruzamento.

Nos animais $1 / 2$ Nelore (heterozigose individual máxima), filhos de vacas da raça Nelore (heterozigose materna nula), o peso foi $0,6 \%$ menor e aumentou, diariamente, $0,8 \%$ menos na pré-desmama em comparação aos filhos de vacas $1 / 2$ Nelore (heterozigose materna máxima). No período pósdesmama, houve inversão, uma vez que os filhos de vacas

Tabela 1 - Resumo das análises de variância, pelo modelo M1, para o peso padronizado para 205 (P205) e para 550 dias de idade (P550) e o ganho médio diário do nascimento à desmama (GMDND) e da desmama ao sobreano (GMDDS)

\begin{tabular}{|c|c|c|c|c|c|c|}
\hline \multirow[t]{2}{*}{ Fonte de variação } & \multirow[t]{2}{*}{ GL } & \multicolumn{2}{|c|}{ Quadrado médio } & \multirow[t]{2}{*}{ GL } & \multicolumn{2}{|c|}{ Quadrado médio } \\
\hline & & P205 & GMDND & & P550 & GMDDS \\
\hline Grupo de contemporâneos & 2.541 & $11.791^{* * *}$ & $272.570^{* * *}$ & 649 & $12.7260^{* * *}$ & $752.482^{* * *}$ \\
\hline $\begin{array}{l}\text { Grupo genético } \\
\text { Idade à desmama }\end{array}$ & 44 & $13.189^{* * *}$ & $285.714^{* * *}$ & 32 & $44.127^{* * *}$ & $284.649^{* * *}$ \\
\hline Linear (L) & 1 & $19.362^{* * *}$ & $464.819^{* * *}$ & & - & - \\
\hline Quadrático $(\mathrm{Q})$ & 1 & $2.729^{* *}$ & $66.621^{*}$ & & - & - \\
\hline Idade ao sobreano & & & & & & \\
\hline Linear $(\mathrm{L})$ & 1 & - & - & 1 & $15.541^{* * *}$ & $96.005^{* * *}$ \\
\hline Idade da vaca ao parto & & & & & & \\
\hline Linear $(\mathrm{L})$ & 1 & $500.619^{* * *}$ & $11.904 .255^{* * *}$ & 1 & $60.102^{* * *}$ & $655.084^{* * *}$ \\
\hline Quadrático (Q) & 1 & $375.912^{* * *}$ & $8.936 .490^{* *}$ & 1 & $48.794^{* * *}$ & $427.754^{* * *}$ \\
\hline Erro & 93.912 & 416 & 9.897 & 39.625 & 956 & 5.885 \\
\hline $\mathrm{R}^{2}$ & & 0,53 & 0,52 & & 0,74 & 0,73 \\
\hline
\end{tabular}

${ }^{*}(\mathrm{P}<0,05) ;{ }^{* *}(\mathrm{P}<0,01) ; \mathrm{e}^{* \star *}(\mathrm{P}<0,0001) ; \mathrm{GL}=$ Graus de liberdade 
Tabela 2 - Número de observações, médias ajustadas por quadrados mínimos e erros-padrão para as raças Aberdeen Angus (A) e Nelore (N) e os produtos de seus cruzamentos para peso ajustado aos 205 (P205) e aos 550 dias de idade (P550) e para ganho médio diário do nascimento à desmama (GMDND) e da desmama ao sobreano (GMDDS)

\begin{tabular}{|c|c|c|c|c|c|c|c|c|}
\hline Bezerro & Touro & Vaca & Obs. & P205(kg) & GMDND(g) & Obs. & P550 (kg) & GMDDS (g) \\
\hline A & A & A & 10.860 & $164 \pm 1$ & $647 \pm 4$ & 5043 & $305 \pm 2$ & $401 \pm 4$ \\
\hline $3 / 16 \mathrm{~N}$ & A & $3 / 8 \mathrm{~N}$ & 417 & $172 \pm 1$ & $691 \pm 6$ & 205 & $299 \pm 2$ & $369 \pm 6$ \\
\hline $3 / 16 \mathrm{~N}$ & $3 / 8 \mathrm{~N}$ & A & 517 & $162 \pm 1$ & $645 \pm 5$ & 280 & $305 \pm 2$ & $399 \pm 5$ \\
\hline $9 / 32 \mathrm{~N}$ & A & $9 / 16 \mathrm{~N}$ & 100 & $172 \pm 2$ & $691 \pm 10$ & - & - & - \\
\hline $9 / 32 \mathrm{~N}$ & $3 / 8 \mathrm{~N}$ & $3 / 16 \mathrm{~N}$ & 101 & $172 \pm 2$ & $694 \pm 10$ & - & - & - \\
\hline $5 / 16 \mathrm{~N}$ & $\mathrm{~A}$ & $5 / 8 \mathrm{~N}$ & 2.483 & $176 \pm 1$ & $714 \pm 3$ & 1020 & $316 \pm 1$ & $394 \pm 3$ \\
\hline $5 / 16 \mathrm{~N}$ & $3 / 8 \mathrm{~N}$ & $1 / 4 \mathrm{~N}$ & 61 & $175 \pm 3$ & $707 \pm 3$ & 40 & $305 \pm 5$ & $378 \pm 12$ \\
\hline $5 / 16 \mathrm{~N}$ & $5 / 8 \mathrm{~N}$ & A & 1.155 & $163 \pm 1$ & $650 \pm 6$ & 612 & $305 \pm 2$ & $423 \pm 5$ \\
\hline $11 / 32 \mathrm{~N}$ & A & $11 / 16 \mathrm{~N}$ & 2.010 & $177 \pm 1$ & $717 \pm 3$ & 1285 & $322 \pm 1$ & $415 \pm 3$ \\
\hline $11 / 32 \mathrm{~N}$ & $3 / 8 \mathrm{~N}$ & $5 / 16 \mathrm{~N}$ & 263 & $170 \pm 1$ & $684 \pm 6$ & 111 & $301 \pm 3$ & $386 \pm 8$ \\
\hline $11 / 32 \mathrm{~N}$ & $11 / 16 \mathrm{~N}$ & A & 315 & $165 \pm 1$ & $659 \pm 7$ & 58 & $302 \pm 5$ & $393 \pm 11$ \\
\hline $3 / 8 \mathrm{~N}$ & A & $3 / 4 \mathrm{~N}$ & 4.713 & $179 \pm 1$ & $726 \pm 3$ & 1635 & $322 \pm 1$ & $413 \pm 3$ \\
\hline $3 / 8 \mathrm{~N}$ & $1 / 4 \mathrm{~N}$ & $1 / 2 \mathrm{~N}$ & 446 & $181 \pm 1$ & $734 \pm 6$ & 87 & $313 \pm 5$ & $383 \pm 11$ \\
\hline $3 / 8 \mathrm{~N}$ & $3 / 8 \mathrm{~N}$ & $3 / 8 \mathrm{~N}$ & 20.180 & $168 \pm 0$ & $675 \pm 2$ & 9315 & $308 \pm 1$ & $393 \pm 2$ \\
\hline $3 / 8 \mathrm{~N}$ & $3 / 4 \mathrm{~N}$ & A & 6.983 & $164 \pm 1$ & $652 \pm 3$ & 3453 & $313 \pm 1$ & $430 \pm 3$ \\
\hline $13 / 32 \mathrm{~N}$ & A & $13 / 16 \mathrm{~N}$ & 126 & $180 \pm 2$ & $729 \pm 10$ & 79 & $324 \pm 4$ & $422 \pm 10$ \\
\hline $13 / 32 \mathrm{~N}$ & $3 / 8 \mathrm{~N}$ & $7 / 16 \mathrm{~N}$ & 328 & $166 \pm 1$ & $664 \pm 6$ & 125 & $309 \pm 3$ & $397 \pm 7$ \\
\hline $7 / 16 \mathrm{~N}$ & $3 / 8 \mathrm{~N}$ & $1 / 2 \mathrm{~N}$ & 6.603 & $179 \pm 0$ & $727 \pm 2$ & - & - & - \\
\hline $7 / 16 \mathrm{~N}$ & $1 / 2 \mathrm{~N}$ & $3 / 8 \mathrm{~N}$ & 66 & $162 \pm 5$ & $645 \pm 25$ & - & - & - \\
\hline $1 / 2 \mathrm{~N}$ & A & $\mathrm{N}$ & 17.883 & $178 \pm 0$ & $721 \pm 2$ & 7476 & $334 \pm 1$ & $440 \pm 3$ \\
\hline $1 / 2 \mathrm{~N}$ & $3 / 8 \mathrm{~N}$ & $5 / 8 \mathrm{~N}$ & 904 & $173 \pm 1$ & $698 \pm 4$ & 464 & $311+2$ & $387 \pm 4$ \\
\hline $1 / 2 \mathrm{~N}$ & $1 / 2 \mathrm{~N}$ & $1 / 2 \mathrm{~N}$ & 648 & $179 \pm 1$ & $727 \pm 7$ & 352 & $312 \pm 2$ & $342 \pm 6$ \\
\hline $1 / 2 \mathrm{~N}$ & $5 / 8 \mathrm{~N}$ & $3 / 8 \mathrm{~N}$ & 106 & $164 \pm 2$ & $652 \pm 11$ & 50 & $259 \pm 5$ & $271 \pm 12$ \\
\hline $9 / 16 \mathrm{~N}$ & $3 / 8 \mathrm{~N}$ & $3 / 4 \mathrm{~N}$ & 141 & $174 \pm 2$ & $707 \pm 9$ & 59 & $311 \pm 4$ & $387 \pm 10$ \\
\hline $9 / 16 \mathrm{~N}$ & $1 / 2 \mathrm{~N}$ & $5 / 8 \mathrm{~N}$ & 22 & $174 \pm 4$ & $706 \pm 22$ & - & - & - \\
\hline $9 / 16 \mathrm{~N}$ & $5 / 8 \mathrm{~N}$ & $1 / 2 \mathrm{~N}$ & 685 & $181 \pm 1$ & $739 \pm 5$ & 237 & $307 \pm 2$ & $366 \pm 6$ \\
\hline $9 / 16 \mathrm{~N}$ & $3 / 4 \mathrm{~N}$ & $3 / 8 \mathrm{~N}$ & 86 & $166 \pm 2$ & $667 \pm 12$ & - & - & - \\
\hline $19 / 32 N$ & $3 / 8 \mathrm{~N}$ & $13 / 16 \mathrm{~N}$ & 61 & $175 \pm 3$ & $711 \pm 14$ & 40 & $313 \pm 6$ & $393 \pm 14$ \\
\hline $19 / 32 N$ & $1 / 2 \mathrm{~N}$ & $11 / 16 \mathrm{~N}$ & 23 & $170 \pm 4$ & $690 \pm 21$ & 19 & $307 \pm 7$ & $362 \pm 18$ \\
\hline $19 / 32 N$ & $11 / 16 \mathrm{~N}$ & $1 / 2 \mathrm{~N}$ & 43 & $177 \pm 4$ & $722 \pm 18$ & - & - & - \\
\hline $5 / 8 \mathrm{~N}$ & $1 / 2 \mathrm{~N}$ & $3 / 4 \mathrm{~N}$ & 971 & $167 \pm 3$ & $672 \pm 12$ & 125 & $308 \pm 7$ & $348 \pm 18$ \\
\hline $5 / 8 \mathrm{~N}$ & $5 / 8 \mathrm{~N}$ & $5 / 8 \mathrm{~N}$ & 1.023 & $176 \pm 1$ & $717 \pm 4$ & 355 & $305 \pm 2$ & $365 \pm 5$ \\
\hline $5 / 8 \mathrm{~N}$ & $3 / 4 \mathrm{~N}$ & $1 / 2 \mathrm{~N}$ & 77 & $183 \pm 3$ & $753 \pm 12$ & 53 & $316 \pm 5$ & $365 \pm 12$ \\
\hline $21 / 32 N$ & $5 / 8 \mathrm{~N}$ & $11 / 16 \mathrm{~N}$ & 555 & $174 \pm 1$ & $708 \pm 5$ & - & - & - \\
\hline $21 / 32 N$ & $11 / 16 \mathrm{~N}$ & $5 / 8 \mathrm{~N}$ & 75 & $177 \pm 2$ & $722 \pm 12$ & - & - & - \\
\hline $11 / 16 \mathrm{~N}$ & $3 / 8 \mathrm{~N}$ & $\mathrm{~N}$ & 12.687 & $170 \pm 0$ & $685 \pm 2$ & 6610 & $314 \pm 1$ & $404 \pm 3$ \\
\hline $11 / 16 \mathrm{~N}$ & $5 / 8 \mathrm{~N}$ & $3 / 4 \mathrm{~N}$ & 92 & $172 \pm 2$ & $696 \pm 11$ & 43 & $314 \pm 5$ & $397 \pm 12$ \\
\hline $11 / 16 \mathrm{~N}$ & $11 / 16 \mathrm{~N}$ & $11 / 16 \mathrm{~N}$ & 63 & $171 \pm 3$ & $694 \pm 14$ & - & - & - \\
\hline $11 / 16 \mathrm{~N}$ & $3 / 4 \mathrm{~N}$ & $5 / 8 \mathrm{~N}$ & 59 & $177 \pm 3$ & $724 \pm 15$ & 40 & $297 \pm 5$ & $319 \pm 13$ \\
\hline $3 / 4 \mathrm{~N}$ & $1 / 2 \mathrm{~N}$ & $\mathrm{~N}$ & 848 & $168 \pm 1$ & $679 \pm 5$ & 386 & $308 \pm 2$ & $381 \pm 5$ \\
\hline $3 / 4 N$ & $3 / 4 \mathrm{~N}$ & $3 / 4 \mathrm{~N}$ & 46 & $168 \pm 4$ & $678 \pm 17$ & - & - & - \\
\hline $3 / 4 \mathrm{~N}$ & $\mathrm{~N}$ & $1 / 2 \mathrm{~N}$ & 560 & $176 \pm 1$ & $718 \pm 7$ & 130 & $303 \pm 4$ & $367 \pm 9$ \\
\hline $13 / 16 \mathrm{~N}$ & $5 / 8 \mathrm{~N}$ & $1 \mathrm{~N}$ & 874 & $168 \pm 1$ & $677 \pm 6$ & 455 & $306 \pm 2$ & $386 \pm 5$ \\
\hline $13 / 16 \mathrm{~N}$ & $\mathrm{~N}$ & $5 / 8 \mathrm{~N}$ & 139 & $181 \pm 2$ & $739 \pm 10$ & 68 & $303 \pm 4$ & $344 \pm 11$ \\
\hline $\mathrm{N}$ & $\mathrm{N}$ & $\mathrm{N}$ & 104 & $162 \pm 2$ & $655 \pm 11$ & - & - & - \\
\hline
\end{tabular}

da raça Nelore foram $7 \%$ mais pesados aos 550 dias e apresentaram ganho de peso diário $29 \%$ maior em comparação aos filhos de vacas $1 / 2$ Nelore, comprovando que, nesta fase, a heterose materna tem pouca influência no desempenho do animal.

Considerando somente os acasalamentos recíprocos (Tabela 2), as maiores diferenças ( $17 \mathrm{~kg}$ para P205 e $82 \mathrm{~g} / \mathrm{dia}$ para GMDND) foram observadas nos animais 7/16 Nelore, sobretudo nos filhos de vacas $1 / 2$ Nelore. Este comportamento foi similar para todos os recíprocos comparados, exceto para os animais $3 / 4$ Nelore filhos de mães $5 / 8$ Nelore, mostrando que, quanto maior a heterozigose materna, melhor o desempenho dos filhos na fase pré-desmama. Para P550 e GMDDS, as maiores diferenças foram verificadas nos animais $1 / 2$ Nelore $(52 \mathrm{~kg}$ e $116 \mathrm{~g} / \mathrm{dia}$, respectivamente), sobretudo nos filhos de vacas da raça Nelore.

Os efeitos genéticos estimados por meio de contrastes entre as médias (Tabela 3) evidenciam que a diferença racial direta estimada (Nelore - Angus) foi negativa para P205 (-1,49) e GMDND $(-7,55)$, indicando que bezerros da raça Angus apresentaram maior peso à desmama e ganharam mais peso na fase pré-desmama $(\mathrm{P}>0,05)$. 
Perotto et al. (1998), estimaram diferença racial positiva favorável à raça Caracu em comparação à Charolês e observaram que bezerros da raça Caracu pesaram mais à desmama que os da raça Charolês, logo, a raça está mais adaptada às condições do estado do Paraná, onde o experimento foi realizado.

Comparando o desempenho de animais originados de cruzamentos recíprocos, com a mesma heterozigose individual, porém com heterozigoses maternas distintas, verifica-se efeito residual da influência materna (Tabela 3 ). Os filhos de mães mestiças apresentaram, invariavelmente, maior peso ou ganho de peso em comparação aos de vacas puras ou mesmo mestiças, porém com menor proporção de heterozigose, tanto na fase pré quanto na pós-desmama, o que confirma afirmação de Koger (1980) de que vacas mestiças apresentam bons desempenhos maternos em ampla gama de condições de criação, efeito decorrente da heterozigose materna, com exceção dos animais $1 / 2$ Nelore filhos de vacas da raça Angus e 3/4 Nelore e 13/16 Nelore filhos de vacas Nelore.

Em contraste, os recíprocos $1 / 2$ Nelore, mesma heterozigose individual e materna, apresentaram desempenho diferente, tanto para as características pré quanto para as pós-desmama, uma vez que as vacas 5/8 Nelore apresentaram resultados superiores aos das $3 / 8$ Nelore (Tabela 3 ).

Animais provenientes do cruzamento de touros $3 / 8$ Nelore com vacas $5 / 8$ Nelore foram $5 \%$ mais pesados (P205) e apresentaram GMDND 7\% maior que o daqueles resultantes do acasalamento recíproco, sugerindo que as vacas $5 / 8$ Nelore, mais adaptadas ao ambiente, expressaram melhor a habilidade materna. De forma semelhante, Perotto et al. (2000), comparando cruzamentos recíprocos entre animais da raça Canchim e Angus no estado do Paraná, verificaram que bezerros $1 / 2$ Angus, filhos de vacas Canchim, foram mais pesados aos 365 dias de vida em comparação aos bezerros 1/2 Angus, filhos de vacas Angus. Da mesma forma, os filhos de touros $3 / 8$ Nelore com vacas $5 / 8$ Nelore foram $7 \%$ mais pesados ao sobreano e ganharam $10 \%$ mais peso (GMDDS), o que, de certa forma, corrobora a sugestão de Muniz \& Queiroz (1999) de que a utilização de touros das raças Brangus e Canchim em cruzamentos com vacas da raça Nelore é uma opção viável para produzir animais mais pesados e com ganhos diários maiores ao ano e ao sobreano.

Os valores de heterose estimados para P205 e GMDND foram significativos $(\mathrm{P}<0,0001)$, exceto para os animais 7/16 (Tabela 3), indicando que o desempenho da geração F1 excedeu a média das raças paternas em $10,50 \mathrm{~kg}(6,44 \%)$ e $48,58 \mathrm{~g} / \mathrm{dia}(7,46 \%)$, respectivamente. Estimativas de heterose inferiores foram relatadas por Perotto et al. (1998), de $7 \mathrm{~kg}$ para P205 (4,62\%) e $39 \mathrm{~g} /$ dia para GMDND (6,74\%), no entanto, estimativas superiores foram observadas por Muniz \& Queiroz (1998) para peso aos 240 dias (8\%) em animais Nelore $\times$ Gelbvieh no estado do Mato Grosso do Sul e por Roso \& Fries (2000) para GMDND $(9,10 \%)$ em animais Nelore $\times$ Angus em diversos estados brasileiros. Como causa desta variação, podem ser considerados os diversos graus de heterozigose individual e materna e os efeitos aditivos de raça individual e materno. Este resultado corrobora o relato de Cartwright \& Carpenter (1961) de que animais resultantes de cruzamento mamam mais vezes ao dia e por períodos maiores.

Os coeficientes de regressão parciais de efeito aditivo de raça individual $\left(\beta_{1} \mathrm{~N}^{\mathrm{I}}\right)$ (Tabela 3 ) comprovam que o aumento do percentual da raça Nelore no cruzamento promoverá redução em P205, P550 e no GMDDS e aumento no GMDND. Os coeficientes de regressão parciais para efeito aditivo de raça materno $\left(\beta_{2} \mathrm{~N}^{\mathrm{M}}\right)$ indicam que, quanto maior o percentual de genes da raça Nelore na vaca, melhor o desempenho do bezerro, logo, as vacas da raça Nelore possuem maior habilidade materna e/ou são mais adaptadas ao meio em que estão inseridas. Este resultado confirma o relatado por Trematore et al. (1998), que, comparando cruzamentos recíprocos entre as raças Nelore e Charolês no estado de São Paulo, observaram melhor desempenho de vacas da raça Nelore.

Os coeficientes de regressão parcial (Tabela 3 ) dos efeitos de heterozigose direta $\left(\beta_{3}\right)$ e materna $\left(\beta_{4}\right)$ comprovam que, ao contrário do observado para P205 e GMDND, $\beta_{3}$ é superior a $\beta_{4}$ para P550 e GMDDS, indicando que a maior influência sobre o desenvolvimento ponderal do bezerro é decorrente da heterozigose direta. Assim, ao se tornar independente da mãe, por ocasião da desmama, o bezerro tem seu desempenho determinado por seu próprio potencial genético,que, em ambiente favorável, é expresso fenotipicamente. $O$ coeficiente $\beta_{3}$ assemelha-se ao resultado encontrado na análise de contrastes realizada para o grupo genético $1 / 2$ Nelore, sugerindo que os modelos 1 e 2 estimam efeitos genéticos semelhantes.

Verifica-se também que há concordância entre $\beta_{3} \mathrm{~N} \times \mathrm{A}^{\mathrm{I}}$ e a heterose da F1 para P205 e GMDND, o que permite afirmar que o contraste $[(1 / 2$ Nelore $+1 / 2$ Nelore $) / 2-$ (Nelore + Aangus)/2] e o coeficiente de regressão parcial dos fenótipos sobre a fração esperada de loci heterozigóticos nos genótipos dos bezerros estimam o mesmo componente genético e, neste caso, segundo Perotto et al. (1998), qualquer dos modelos testados pode ser utilizado para estimar características de desempenho para os animais. 
Tabela 3 - Estimativas de efeitos genéticos do peso à desmama ajustado para 205 dias (P205), do peso ao sobreano ajustado para 550 dias de idade (P550), do ganho médio diário do nascimento à desmama (GMDND) e do ganho diário da desmama ao sobreano em bovinos das raças Aberdeen Angus $(A)$, Nelore $(N)$ e seus cruzamentos

\begin{tabular}{|c|c|c|c|c|}
\hline \multirow[t]{2}{*}{ Efeito } & \multicolumn{4}{|c|}{ Característica } \\
\hline & P205 & GMDND & P550 & GMDDS \\
\hline Dif. racial direta & $-1,49$ & $-7,55$ & - & - \\
\hline Dif. recíproca 3/16 & $9,40 * * *$ & $45,71 * * *$ & $11,76^{*}$ & $28,67^{\mathrm{NS}}$ \\
\hline Dif. recíproca 5/16 & $13,09 * * *$ & $63,82 * * *$ & $20,39 * * *$ & $22,83^{\mathrm{NS}}$ \\
\hline Dif. recíproca $11 / 32$ & $11,99 * * *$ & $58,25 * * *$ & $8,82 * * *$ & $20,28 * *$ \\
\hline Dif. recíproca 3/8 & $15,34 * * *$ & $74,76^{* * *}$ & $51,67 * * *$ & $115,71 * * *$ \\
\hline Dif. recíproca 7/16 & $16,71 * *$ & $71,84 * *$ & - & - \\
\hline Dif. recíproca $1 / 2$ & $9,36 * *$ & $45,84 * *$ & $51,67 * * *$ & $115,71 * * *$ \\
\hline Dif. recíproca $9 / 16^{1}$ & $8,11 * *$ & $39,54 * *$ & - & - \\
\hline Dif. recíproca $9 / 16^{2}$ & $-6,82$ & $-33,43$ & - & - \\
\hline Dif. recíproca 19/32 & $-6,50$ & $-31,80$ & - & - \\
\hline Dif. recíproca 21/32 & $-2,74$ & $-13,40$ & - & - \\
\hline Dif. recíproca $5 / 8$ & $-16,31 * * *$ & $-80,10 * * *$ & $-8,03^{\mathrm{NS}}$ & $-16,99^{\mathrm{NS}}$ \\
\hline Dif. recíproca $11 / 16$ & $-5,65$ & $-27,67$ & $17,73^{*}$ & $77,24 * * *$ \\
\hline Dif. recíproca 3/4 & $-8,16^{* * *}$ & $-39,66 * * *$ & $4,94^{\mathrm{NS}}$ & $14,97^{\mathrm{NS}}$ \\
\hline Dif. recíproca 13/16 & $-12,82 * * *$ & $-62,41 * * *$ & $2,69^{\mathrm{NS}}$ & $41,69 * *$ \\
\hline Heterose $1 / 2$ & $10,50 * * *$ & $48,58 * * *$ & - & - \\
\hline Heterose $3 / 4$ & $7,88 * * *$ & $40,70 * * *$ & - & - \\
\hline Heterose $5 / 8$ & $12,47 * * *$ & $63,03 * * *$ & - & - \\
\hline Heterose $3 / 16$ & $4,00 * *$ & $45,71 * *$ & - & - \\
\hline Heterose $9 / 32$ & $9,09 * * *$ & $41,52 * * *$ & - & - \\
\hline Heterose 5/16 & $8,65 * * *$ & $39,53 * * *$ & - & - \\
\hline Heterose $11 / 32$ & $7,81 * * *$ & $35,52 * * *$ & - & - \\
\hline Heterose $3 / 8$ & $9,94 * * *$ & $45,93 * * *$ & - & - \\
\hline Heterose $13 / 32$ & $9,91 * * *$ & $45,69 * * *$ & - & - \\
\hline Heterose 7/16 & $7,83 * *$ & $35,44 *$ & - & - \\
\hline Heterose 9/16 & $10,59 * * *$ & $53,93 * * *$ & - & - \\
\hline Heterose 19/32 & $11,16 * * *$ & $56,66 * * *$ & - & - \\
\hline Heterose $21 / 32$ & $12,64 * * *$ & $64,02 * * *$ & - & - \\
\hline Heterose $11 / 16$ & $9,59 * * *$ & $39,53 * * *$ & - & - \\
\hline Heterose $13 / 16$ & $11,99 * * *$ & $57,34 * * *$ & - & - \\
\hline Intercepto & $167,62 * * *$ & $664,39 * * *$ & $306,04 * * *$ & $392,08 * * *$ \\
\hline$\beta_{1} \mathrm{~N}^{\mathrm{I}}$ & $-31,10 * * *$ & $139,89 * * *$ & $-129,67 * * *$ & $-287,02 * * *$ \\
\hline$\beta_{2} \mathrm{~N}^{\mathrm{M}}$ & $4,80 * * *$ & $22,86 * * *$ & $40,43 * * *$ & $111,73 * * *$ \\
\hline$\beta_{3} \mathrm{~N} \times \mathrm{A}^{\mathrm{I}}$ & $13,29 * * *$ & $66,30 * * *$ & $37,91 * * *$ & $64,52 * * *$ \\
\hline 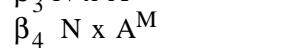 & $16,40 * * *$ & $85,01 * * *$ & $17,71 * * *$ & $20,72 * * *$ \\
\hline $\mathrm{R}^{2}$ & 0,27 & 0,22 & $306,04 * * *$ & $392,08 * * *$ \\
\hline
\end{tabular}

${ }^{*} \mathrm{P}<0,05 ;{ }^{*} \mathrm{P}<0,01 ;{ }^{* * *} \mathrm{P}<0,0001$ e $\mathrm{NS}=$ não-significativo; 1 - Contrastando $(3 / 8 \mathrm{~N} \times 3 / 4 \mathrm{~N})$ vs $(3 / 4 \mathrm{~N} \times 3 / 8 \mathrm{~N}) ; 2$ - Contrastando (1/2N + 1/2A x 5/8N) vs

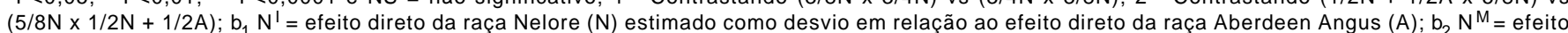
materno da raça $N$ estimado como desvio em relação ao efeito materno da raça $A / N ; b_{3} N \times A^{\prime}=$ efeito da heterozigose $N \times A$ no genótipo do indivíduo; $b_{4}$ $\mathrm{N} \times \mathrm{A}^{\mathrm{M}}=$ efeito da heterozigose $\mathrm{N} \times \mathrm{A}$ no genótipo da mãe do indivíduo.

O coeficiente de regressão parcial de heterozigose materna $\boldsymbol{\beta}_{4} \times \mathrm{A}^{\mathrm{M}}$ ) (Tabela 3) sugere que, quanto maior a heterozigose da vaca, maior o desenvolvimento do bezerro noperíodo pré-desmama. Resultados similares foram relatados por Cundiff (1974) para cruzamentos entre as raças Hereford, Angus e Shorthorn. Esses autores comprovaram que os efeitos de heterozigose materna foram significativos; vacas mestiças apresentaram maior produção de leite, além de maior curva de lactação, o que influenciou o desempenho do bezerro até a desmama.

As médias estimadas pelo modelo 1 e as preditas pelo modelo 2 foram estatisticamente iguais $(\mathrm{P}>0,01)$ para $\mathrm{P} 205$, P550 e GMDDS. Comparando as estimativas de desempenho dos grupos genéticos, obtidas pelos modelos 1 e 2 na pré-desmama (Tabela 4), verifica-se que as maiores diferenças entre estimativas obtidas foram $21 \mathrm{~kg}$ e $172 \mathrm{~g} / \mathrm{dia}$ e equivalem a 12 e $24 \%$ das maiores médias, respectivamente, para P205 e P550. Esses valores diferem dos relatados por Abdel-Aziz et al. (2003), que, adotando modelos semelhantes para cruzamentos entre as raças Afrikaner, Charolês, Hereford, Angus e Sindi, na África do Sul, relataram que a maior diferença para peso à desmama foi 9,8\% e, para GMDND, 10,3\%.

As maiores diferenças entre as médias estimadas (M1) e as preditas (M2) para o período pós-desmama foram $33 \mathrm{~kg}$ para P550 e $97 \mathrm{~g} /$ dia para GMDDS. Os valores preditosforam sempre maiores que aqueles estimados pelo modelo 1 para as quatro características estudadas. Os erros-padrão dos 
Tabela 4 - Valores médios de desempenho estimados pelo modelo 1 (M1) e preditos pelo modelo 2 (M2) para o peso ajustado para 205 (P205) e 550 (P550) dias de idade e o ganho médio diário do nascimento à desmama (GMDND) e da desmama ao sobreano (GMDDS) nas raças Aberdeen Angus (A), Nelore (N) e seus cruzamentos

\begin{tabular}{|c|c|c|c|c|c|c|c|}
\hline \multicolumn{4}{|c|}{ Grupo genético } & \multicolumn{2}{|c|}{ P205 (kg) } & \multicolumn{2}{|c|}{ GMDND (g) } \\
\hline Bezerro & $\mathrm{N}$ & Touro & Vaca & M1 & M2 & M1 & M2 \\
\hline A & 10.860 & A & A & $164 \pm 1$ & $168 \pm 2$ & $647 \pm 4$ & $664 \pm 9$ \\
\hline $\mathrm{N}$ & 104 & $\mathrm{~N}$ & $\mathrm{~N}$ & $162 \pm 2$ & $141 \pm 2$ & $655 \pm 1$ & $827 \pm 9$ \\
\hline $1 / 2 \mathrm{~N}$ & 17.883 & $\mathrm{~A}$ & $\mathrm{~N}$ & $178 \pm 0$ & $170 \pm 2$ & $721 \pm 2$ & $824 \pm 9$ \\
\hline $11 / 16 \mathrm{~N}$ & 12.687 & $3 / 8 \mathrm{~N}$ & $\mathrm{~N}$ & $170 \pm 0$ & $159 \pm 2$ & $685 \pm 2$ & $825 \pm 9$ \\
\hline $5 / 8 \mathrm{~N}$ & 1.023 & $5 / 8 \mathrm{~N}$ & $5 / 8 \mathrm{~N}$ & $176 \pm 1$ & $170 \pm 2$ & $717 \pm 4$ & $861 \pm 9$ \\
\hline $7 / 16 \mathrm{~N}$ & 66 & $3 / 8 \mathrm{~N}$ & $1 / 2 \mathrm{~N}$ & $179 \pm 0$ & $179 \pm 2$ & $727 \pm 2$ & $855 \pm 9$ \\
\hline $3 / 8 \mathrm{~N}$ & 6.983 & $3 / 4 \mathrm{~N}$ & A & $164 \pm 0$ & $166 \pm 2$ & $652 \pm 3$ & $756 \pm 9$ \\
\hline $3 / 8 \mathrm{~N}$ & 4.713 & $\mathrm{~A}$ & $3 / 4 \mathrm{~N}$ & $179 \pm 1$ & $178 \pm 2$ & $726 \pm s 3$ & $826 \pm 9$ \\
\hline $3 / 8 \mathrm{~N}$ & - & $1 / 2 \mathrm{~N}$ & $1 / 4 \mathrm{~N}$ & - & $172 \pm 2$ & - & $798 \pm 9$ \\
\hline $1 / 2 \mathrm{~N}$ & - & $\mathrm{N}$ & A & - & $165 \pm 2$ & - & $801 \pm 9$ \\
\hline $11 / 16 \mathrm{~N}$ & - & $\mathrm{N}$ & $3 / 8 \mathrm{~N}$ & - & $169 \pm 2$ & - & $874 \pm 9$ \\
\hline $7 / 16 \mathrm{~N}$ & - & $1 / 2 \mathrm{~N}$ & $3 / 8 \mathrm{~N}$ & - & $175 \pm 2$ & - & $831 \pm 9$ \\
\hline \multicolumn{4}{|c|}{ Grupo genético } & \multicolumn{2}{|c|}{ P550 (kg) } & \multicolumn{2}{|c|}{ GMDDS (g) } \\
\hline Bezerro & $\mathrm{N}$ & Touro & Vaca & M1 & M2 & M1 & M2 \\
\hline A & 5.043 & A & A & $305 \pm 2$ & $306 \pm 2$ & $401 \pm 4$ & $392 \pm 3$ \\
\hline $1 / 2 \mathrm{~A}$ & 7.476 & A & $\mathrm{N}$ & $334 \pm 1$ & $320 \pm 2$ & $440 \pm 3$ & $425 \pm 3$ \\
\hline $11 / 16 \mathrm{~N}$ & 6.610 & $3 / 8 \mathrm{~N}$ & $\mathrm{~N}$ & $314 \pm 1$ & $281 \pm 2$ & $404 \pm 3$ & $347 \pm 3$ \\
\hline $5 / 8 \mathrm{~N}$ & 355 & $5 / 8 \mathrm{~N}$ & $5 / 8 \mathrm{~N}$ & $305 \pm 2$ & $281 \pm 2$ & $365 \pm 5$ & $328 \pm 3$ \\
\hline $5 / 8 \mathrm{~N}$ & 53 & $3 / 4 \mathrm{~N}$ & $1 / 2 \mathrm{~N}$ & - & $306 \pm 2$ & - & $375 \pm 3$ \\
\hline $7 / 16 \mathrm{~N}$ & - & $3 / 4 \mathrm{~N}$ & A & $313 \pm 1$ & $286 \pm 2$ & $430 \pm 3$ & $333 \pm 3$ \\
\hline $3 / 8 \mathrm{~N}$ & 1.635 & A & $3 / 4 \mathrm{~N}$ & $322 \pm 1$ & $325 \pm 2$ & $413 \pm 3$ & $427 \pm 3$ \\
\hline $3 / 8 \mathrm{~N}$ & - & $1 / 2 \mathrm{~N}$ & $1 / 4 \mathrm{~N}$ & - & $295 \pm 2$ & - & $355 \pm 3$ \\
\hline $3 / 8 \mathrm{~N}$ & - & $\mathrm{N}$ & A & - & $279 \pm 2$ & - & $313 \pm 3$ \\
\hline $1 / 2 \mathrm{~N}$ & - & $\mathrm{N}$ & $3 / 8 \mathrm{~N}$ & - & $269 \pm 2$ & - & $293 \pm 3$ \\
\hline $11 / 16 \mathrm{~N}$ & - & $1 / 2 \mathrm{~N}$ & $3 / 8 \mathrm{~N}$ & - & $297 \pm 2$ & - & $356 \pm 3$ \\
\hline
\end{tabular}

valores preditos foram maiores que aqueles dos valores estimados, o que pode ser atribuído, em parte, segundo Abdel-Aziz et al. (2003), ao fato de que a variância da predição é a variância da estimação mais a dos valores preditos.

Apesar de os coeficientes de regressão obtidos pelo modelo 2 explicarem, em parte, os resultados estimados pelo modelo 1 e as médias serem estatisticamente iguais, utilizar informações provenientes de dados não-experimentais para a predição do desempenho não é recomendável até que mais estudos sejam realizados com diferentes constituições genéticas e em diferentes rebanhos, o que fornecerá resultados mais consistentes e acurados.

Os fatores de inflação da variância (FIV) para P205 foram 2,759 para efeito aditivo de raça individual; 3,237 para efeito aditivo de raça materno; 1,946 para efeito de heterozigose individual e 1,103 para efeito de heterozigose materna; e para P550 foram 2,968 para efeito aditivo de raça individual; 3,217 para efeito aditivo de raça materno; 1,900 para efeito de heterozigose individual e 1,061 para efeito de heterozigose materna. Esses resultados sugerem ausência do efeito de multicolineariedade entre essas variáveis, o que, teoricamente, não prejudica a utilização da análise de regressão multivariada, apesar dos altos erros-padrão encontrados. Mesmo assim, recomenda-se cautela no uso desses resultados.

\section{Conclusões}

Os desempenhos diferenciados entre os mestiços de composições genéticas distintas na pré e na pós-desmama indicam que o desempenho do animal depende não somente da heterose direta, mas também do grau de heterose materna, principalmente no período pré-desmama. Entretanto, a manutenção de elevados níveis de heterozigose direta é desejável, pois, na fase pós-desmama, proporciona maiores ganhos médios diários. Portanto, as heteroses, tanto direta quanto materna devem ser incluídas nos modelos de avaliação de animais mestiços. O efeito materno nos produtos de acasalamentos recíprocos foi maior nas vacas $1 / 2$ Nelore, todavia, as médias apresentaram tendência de crescimento com o aumento da proporção de genes da raça Nelore na vaca, sugerindo que estes animais têm maior capacidade adaptativa às regiões em estudo. As médias estimadas estatisticamente iguais às preditas para os pesos padro- 
nizados para 205 e 550 dias e para o ganho médio diário da desmama ao sobreano sugerem que os dois modelos utilizados permitem estimar os mesmos parâmetros.

\section{Literatura Citada}

ABDEL-AZIZ, M.; SCHOEMAN, S.J.; JORDAN, G.F. Estimation of additive, maternal and on additive genetics effects of preweaning growth traits in a multbreed beef cattle project. Animal Science Journal, v.74, p.169-179, 2003.

ALBUQUERQUE, L.G.; ELER, J.P.; COSTA, J.R.P. et al. Produção de leite e desempenho do bezerro na fase de aleitamento em três raças bovinas de corte. Revista Brasileira de Zootecnia, v.22, n.5, p.745-754, 1993.

ALENCAR, M.M. Relação entre produção de leite da vaca e desempenho do bezerro nas raças Canchim e Nelore. Revista Brasileira de Zootecnia, v.18, n.2, p.146-156, 1989.

ALENCAR, M.M.; BARBOSA, P.F.; TULLIO, R.R. et al. Peso a desmama de bezerros da raça Nelore e cruzados Canchim x Nelore e Marchigiana x Nelore. Revista Brasileira de Zootecnia, v.24, n.6, p.917-925, 1995.

ALENCAR, M.M.; TREMATORE, R.L.; OLIVEIRA, J.A.L. et al. Características de crescimento até a desmama de bovinos da raça Nelore e cruzados Charolês x Nelore. Revista Brasileira de Zootecnia, v.27, n.1, p.40-46, 1998.

BARBOSA, P.F.; ALENCAR, M.M. Sistema de cruzamentos em bovinos de corte: estado da arte e necessidades de pesquisa. In: REUNIÃO ANUAL DA SOCIEDADE BRASILEIRA DE ZOOTECNIA, 32., 1995, Brasília. Anais... Brasília: Sociedade Brasileira de Zootecnia, 1995. p.681-683.

CARTWRIGHT, T.C.; CARPENTER, J.A. Effect of nursing habits on calf weights. Journal of Animal Science, v.2, p.904, 1961.

CAMPOS, L.T.; FRIES, L.A. Efeitos ambientais sobre o ganho pósdesmama em bovinos de corte. I) Idade da mãe. In: REUNIÃO ANUAL DA SOCIEDADE BRASILEIRA DE ZOOTECNIA, 26., 1989, Porto Alegre. Anais... Porto Alegre: Sociedade Brasileira de Zootecnia, 1989. p.367

CUNDIFF, L.C.; GREGORY, K.E.; SCHWULST, F.J. et al. Effects of heterosis on maternal performance and milk production in Hereford, Angus and Shorthorn cattle. Journal of Animal Science, v.38, n.4, p.729-745, 1974.

DIAS, L.T.; EL FARO, L.; ALBUQUERQUE, L.G. Estimativas de herdabilidade para perímetro escrotal de animais da raça Nelore. Revista Brasileira de Zootecnia, v.32, n.6, p.1878-1882, 2003 (supl. 2).

FREUND, R.J.; WILSON, W.J. Regression analysis : statistical modeling of a response variable. San Diego: Academic Press, 1998. 444p.

FRIES, L.A.; JOHNSTON, D.J.; HEARNSHAW, H. et al. Evidence of epistatic effects on weaning weight in crossbred beef cattle. AsianAustralasian Journal of Animal Sciences, v.13, p.242, 2000 (supl. B).
KOGER, M. Effective crossbreeding systems utilizing zebu cattle. Journal of Animal Science, v.50, p.1215-1220, 1980.

LEAL, J.J.B. Comportamento de Novilhas Braford F1 (Nelore x Hereford - Tabapuã x Hereford - Gir x Hereford - Guzerá $x$ Hereford) à desmama do primeiro produto. Bagé: Embrapa Pecuária Sul, 2000. (Comunicado Técnico, 31).

MEYER, K.; CARRICK, M.J.; DONNELY, B.J.P. Genetic parameters for milk production of Australian beef cows and weaning weight of their calves. Journal of Animal Science, v.72, p.11551165, 1994.

MUNIZ, C.A.S.; QUEIROZ S.A. Avaliação do peso a desmama e do ganho médio de peso de bezerros cruzados, no estado do Mato Grosso do Sul. Revista Brasileira de Zootecnia, v.27, n.3, p.504-512, 1998.

MUNIZ, C.A.S.; QUEIROZ S.A. Avaliação de características de crescimento pós-desmama de animais Nelore puros e cruzados no estado do Mato Grosso do Sul. Revista Brasileira de Zootecnia, v.28, n.4, p.713-720, 1999.

PASCHAL, J.C.; SANDERS, J.O.; KERR, J.L. et al. Postweaning and feedlot growth and carcass characteristics of Angus-, Gray Brahman-, Gir-, Indu-Brazil, Nellore-, and Red Brahman sired F1 calves. Journal of Animal Science, v.73, p.373-380, 1994.

PERotTO, D.; CUBAS, A.C.; MOLETTA, J.L. et al. Pesos ao nascimento e á desmama e ganho de peso do nascimento a desmama de bovinos Charolês, Caracu e cruzamentos recíprocos. Revista Brasileira de Zootecnia, v.27, n.4, p.730-737, 1998.

PEROTTO, D.; CUBAS, A.C.; MOLETTA, J.L. et al. Heterose sobre os pesos de bovinos Canchim e Aberdeen Angus e de seus cruzamentos recíprocos. Pesquisa Agropecuária Brasileira, v. 35, n.12, p.2511-2520, 2000.

ROSO, V.M.; FRIES, L.A. Avaliação das heteroses materna e individual sobre o ganho de peso do nascimento ao desmame em bovinos Angus x Nelore. Revista Brasileira de Zootecnia, v. 29, n.3, p.732-737, 2000.

ROSO, V.M.; SCHENKEL, F.S.; MILLER, S.P. Estimação de efeitos genéticos na presença de multicolinearidade. In: REUNIÃO ANUAL DA SOCIEDADE BRASILEIRA DE ZOOTECNIA, 42., 2005, Goiânia. Anais... Goiânia: Sociedade Brasileira de Zootecnia, 2005. (CD-ROM).

STATISTICAL ANALYSIS SYSTEM - SAS. User's guide : statistics. Cary: SAS Institute, 2001. (CD-ROM).

SKRYPZECK, H.; SCHOEMAN, S.J.; JORDAAN, J.F. et al. Estimates of crossbreeding parameters in a multibreed beef cattle crossbreeding project. South African Journal of Animal Science, v.30, n.3, p.193-203, 2000.

TREMATORE, R.L.; ALENCAR, M.M.; BARBOSA, P.B. et al. Estimativas de efeitos aditivos e heteróticos para características de crescimento pré-desmama em bovinos Charolês-Nelore. Revista Brasileira de Zootecnia, v.27, n.1, p.87-94, 1998.

WOLF, J.; DISTL, O.; HYAMAR, J. et al. Crossbreeding in farm animals. V Analysis of crossbreeding plans with secondary crossbreed generations. Journal of Animal Breeding and Genetics, v.112, p.81-94, 1995. 